\title{
AEROGEL INSULATION APPLICATIONS FOR LIQUID HYDROGEN LAUNCH VEHICLE TANKS
}

\author{
J. E. Fesmire, J. Sass \\ NASA Kennedy Space Center \\ Kennedy Space Center, FL, 32899, USA
}

\begin{abstract}
Aerogel based insulation systems for ambient pressure environments were developed for liquid hydrogen (LH2) tank applications. Solutions to thermal insulation problems were demonstrated for the Space Shuttle External Tank (ET) through extensive testing at the Cryogenics Test Laboratory. Demonstration testing was performed using a 1/10th scale ET LH2 intertank unit and liquid helium as the coolant to provide the $20 \mathrm{~K}$ cold boundary temperature. Cryopumping tests in the range of $20 \mathrm{~K}$ were performed using both constant mass and constant pressure methods. Long-duration tests (up to 10 hours) showed that the nitrogen mass taken up inside the intertank is reduced by a factor of nearly three for the aerogel insulated case as compared to the un-insulated (bare metal flight configuration) case. Test results including thermal stabilization, heat transfer effectiveness, and cryopumping confirm that the aerogel system eliminates free liquid nitrogen within the intertank. Physisorption (or adsorption) of liquid nitrogen within the fine pore structure of aerogel materials was also investigated. Results of a mass uptake method show that the sorption ratio (liquid nitrogen to aerogel beads) is about 62 percent by volume. A novel liquid nitrogen production method of testing the liquid nitrogen physical adsorption capacity of aerogel beads was also performed to more closely approximate the actual launch vehicle cooldown and thermal stabilization effects within the aerogel material. The extraordinary insulating effectiveness of the aerogel material shows that cryopumping is not an open-cell mass transport issue but is strictly driven by thermal communication between warm and cold surfaces. The new aerogel insulation technology is useful to solve heat transfer problem areas and to augment existing thermal protection systems on launch vehicles. Examples are given and potential benefits for producing launch systems that are more reliable, robust, reusable, and efficient are outlined.
\end{abstract}

\section{INTRODUCTION}

A recurring problem on space launch vehicles continues to be the uninsulated areas on the cryogenic propellant tanks and feed-lines that allow the condensation of air or the formation of ice. These areas, including flange joints, bracket supports, expansion bellows, and other cavities, are uninsulated by design. Conventional thermal insulation materials, if applied to these critical system components could lead to worse damage 
during flight by restricting mechanical articulations or by imperfectly sealing these cavities. New aerogel-based thermal insulation systems have been developed for critical locations on launch vehicles. Aerogel materials and a flight vehicle application for liquid oxygen (LO2) feedline bellows has been previously described [1]. Recent work has focused on ambient pressure insulation systems for liquid hydrogen tank dome applications. This research study was motivated by the need for solving a long-standing problem on the liquid hydrogen (LH2) tank dome area of the Space Shuttle External Tank.

Post-flight photographic examination of External Tanks has shown a high concentration of foam debris in the area around the intertank to LH2 tank flange joint. In the cavity formed between the intertank wall, flange, and the LH2 tank dome, termed the crevice as shown in Figure 1, there exists a periphery of bare metal at $20 \mathrm{~K}$. The nitrogen purge gas within the intertank volume condenses on this cold surface. The liquefied nitrogen (LN2) continues to accumulate in the crevice in the hours of propellant loading and conditioning prior to launch. A small amount of solid nitrogen (SN2) also forms on the colder side of the crevice. The LN2 can then seep through the flange joint to the underside of the foam and into voids in the foam. Upon launch the LN2 can vaporize due to the ullage pressurization (hot gas), aerodynamic heating, and reduction in ambient pressure. From the liquid to gas expansion of nitrogen, the potential exists for voids or discontinuities within the foam to pressurize and cause damaging foam debris during flight. In addition, the lift-off mass penalty is significant at up to a combined $230 \mathrm{~kg}$ of liquid and solid nitrogen.
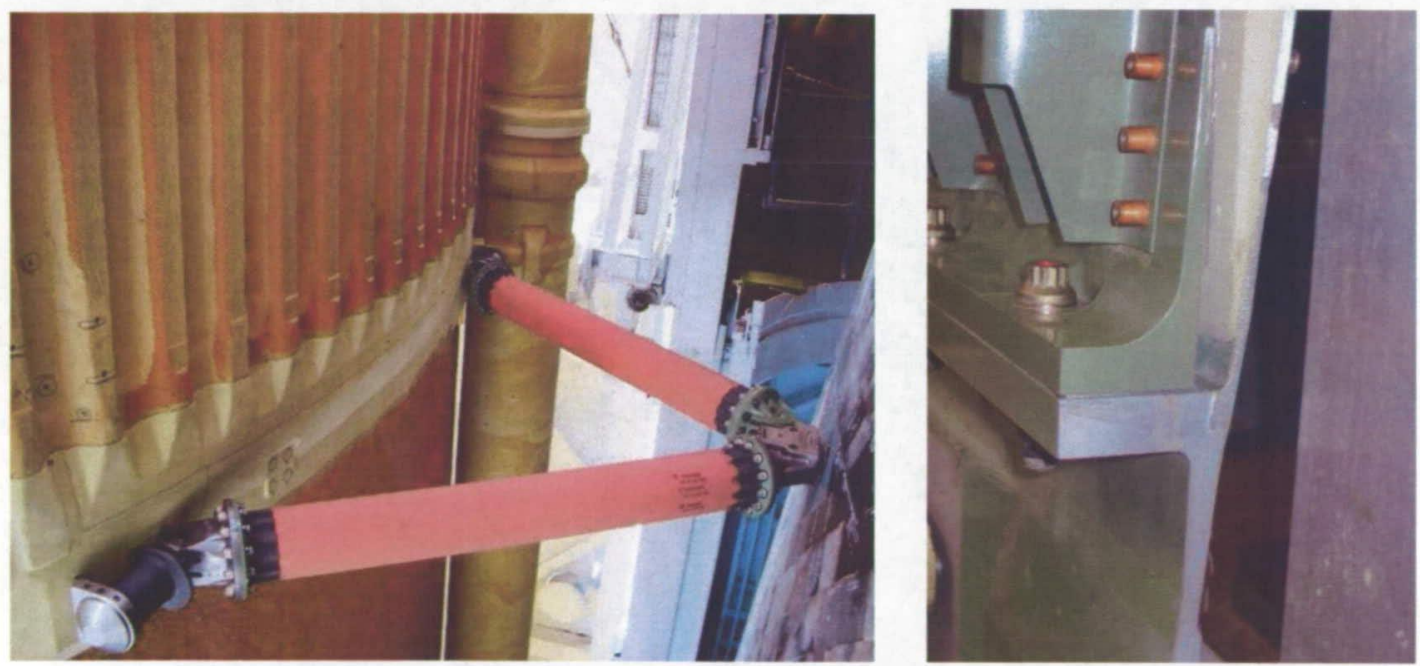

Figure 1. A view of Space Shuttle External Tank LH2 intertank flange area on Orbiter attachment side is shown on the left. A cutaway of the intertank flange area showing the crevice is given on the right.

A thermal insulation system using bulk-fill aerogel material has been successfully developed and demonstrated a $1 / 10^{\text {th }}$ scale model of the LH2 intertank area. The aerogel insulation system and method of application stems from several years of material research investigations combined with demonstration testing at the Cryogenics Test Laboratory. 


\section{EXPERIMENTAL INVESTIGATIONS}

Experimental investigations of the aerogel material included performance testing of cryogenic thermal conductivity, mass transport (cryopumping), and physical adsorption. Other materials in addition to the bulk-fill aerogel were studied but are beyond the scope of this article.

\section{Material Properties and Characterization}

Aerogel beads in bulk-fill form act as the thermal insulation element of the system. The small surface area of the LH2 tank dome not covered by the spray-on foam (SOFI) material is insulated with this very low thermal conductivity material. The aerogel is an open cell material with an average pore size of 20 nanometers and a surface area of approximately $800 \mathrm{~m}^{2} / \mathrm{g}$. The average size of the spherical beads is $1-\mathrm{mm}$ as indicated in Figure 19. With a particle density of $140 \mathrm{~kg} / \mathrm{m}^{3}$ and a bulk density of about $80 \mathrm{~kg} / \mathrm{m}^{3}$ an interstitial space of roughly $60 \%$ is typical. The aerogel beads are lightweight, easy to handle and convey, and present no personnel safety hazard. The bead particles pack well mechanically, have a high level of elastic compression capability, and are generally reusable. The material is commercially available on a largescale from Cabot Corporation under the trademark Nanogel [2]. The material is lightweight, easy to handle and convey, and presents no safety hazard to personnel.

This material has a very high sorption capacity for nitrogen molecules. All of the nitrogen mass that is added during cooldown is sequestered inside the nanoporous structure of the aerogel instead of condensing and forming a liquid. A key advantage of the aerogel system is that it will remain fully breathable, loose, and friable for the entire loading and launch process. Past attempts to solve the problem of LN2 in the intertank have relied upon creating a perfect seal to isolate the nitrogen from the cold surfaces. These past attempts were ultimately not successful due to the difficulty of remaining sealed when exposed to the tremendous thermal gradient during operation. A failed seal is potentially worse than no seal at all, because the liquid has the long pre-launch time frame to enter and only the launch timeframe to escape through the same failure point as a gas during ascent. Since the aerogel insulation system is not intended to seal out nitrogen, the nitrogen entrapment issue during ascent is avoided.

\section{Thermal Conductivity}

Thermal characterization of the aerogel materials in various configurations has been accomplished using insulation test cryostats $[3,4]$. The temperature profile for a 25 $\mathrm{mm}$ thickness of aerogel beads for an ambient pressure test is given in Figure 2. The 2.5$\mathrm{mm}$ layer position gives a temperature difference of approximately $57 \mathrm{~K}$. We can therefore infer from this information that the thickness required to develop isotherm in the range of $63 \mathrm{~K}$ (SN2) to $77 \mathrm{~K}$ (LN2) from a cold boundary of $20 \mathrm{~K}$ (LH2) is less than $2.5 \mathrm{~mm}$ because of the increased effectiveness at lower temperatures [5]. 


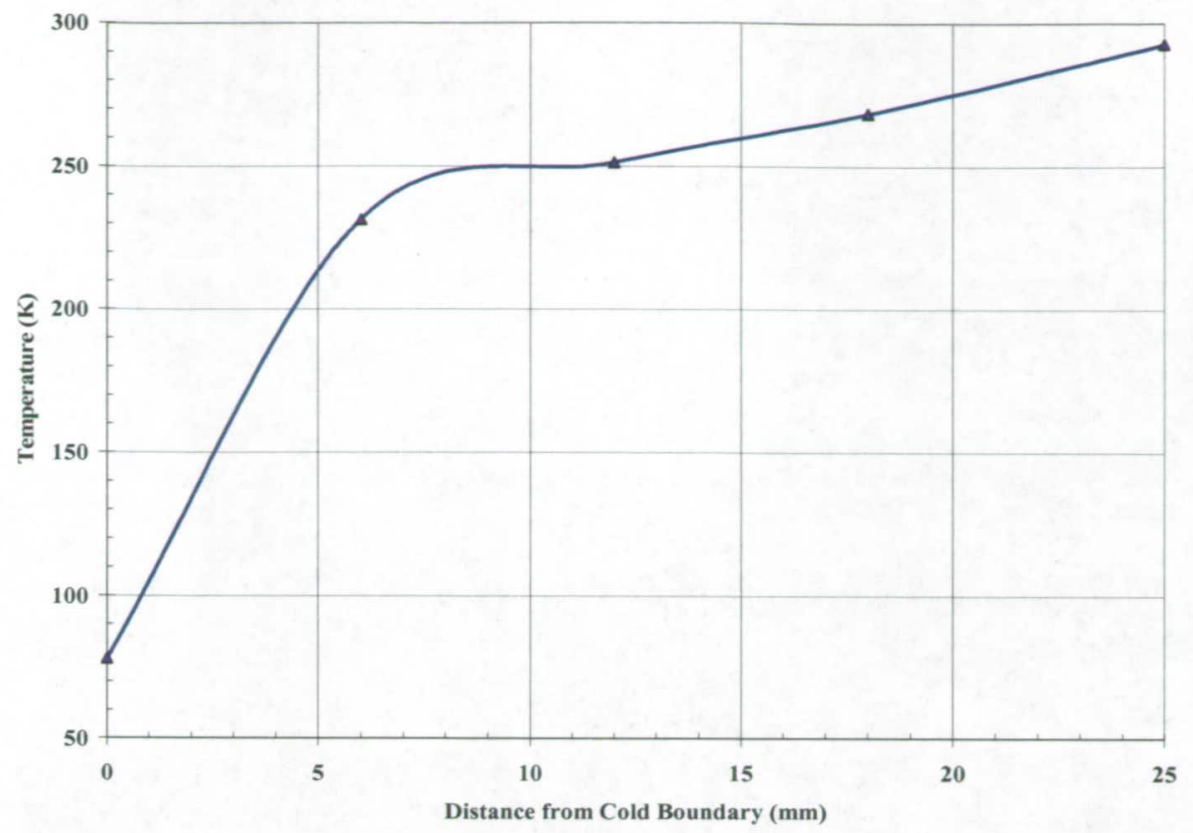

Figure 2. Temperature distribution through $25-\mathrm{mm}$ thickness of aerogel beads with boundary temperatures of $77 \mathrm{~K}$ and $293 \mathrm{~K}$ at ambient pressure (the residual gas is nitrogen).

\section{Mass Transport (Cryopumping)}

Cryopumping experiments for a cold boundary temperature of $77 \mathrm{~K}$ were performed using both a closed chamber apparatus (cryostat) and an open chamber apparatus (cold column). Results show that stabilization and isotherms form after cooldown in approximately 2 hours and 3 hours, respectively, as previously reported [1]. Cryopumping effects between the boundary temperatures of $300 \mathrm{~K}$ and $20 \mathrm{~K}$ were observed through the demonstration testing using liquid helium (LHe) and were found to follow a similar pattern of stabilization in 2-3 hours from cooldown.

\section{Physical Adsorption}

The physical adsorption capacity of bulk-fill aerogel for liquid nitrogen was measured using a number of methods. The mass uptake method (cup test) is shown in Figure 3 where the aerogel material is placed in a bottom-perforated cup, fully saturated using $\mathrm{LN} 2$, and then placed on a precision scale for measurement of the weight gained. Nitrogen is taken up by the nano-sized pores of the aerogel as the material surfaces are cooled. This process is termed physisorption meaning that layers of nitrogen molecules are internally stacked within the porous structure. Results show that the sorption ratio (nitrogen to aerogel) is about 62 percent by volume. The sorption ratio on a mass basis is about seven to one. For the ET intertank case, the available sorption capacity for nitrogen is many times more than the minimum necessary. The additional amount will provide additional insulating benefit while causing no adverse effect. 


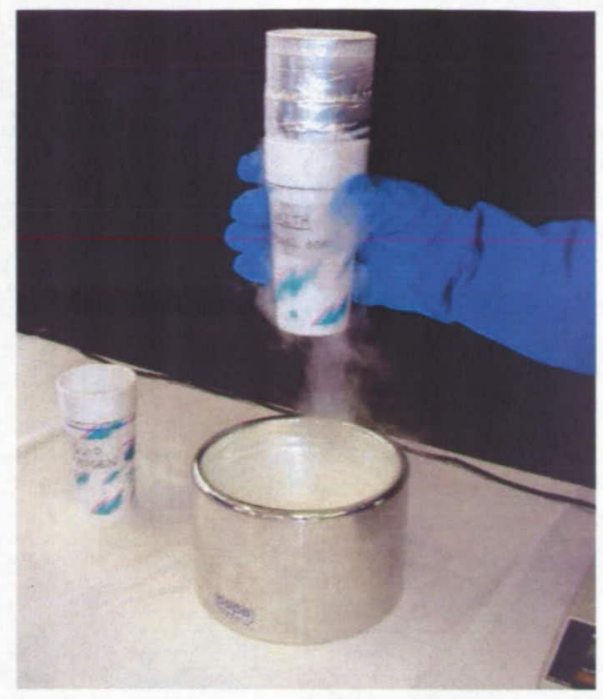

Figure 3. The nitrogen sorption capacity of the aerogel material is measured by the mass uptake method using liquid nitrogen (cup test).

\section{Free Liquid Nitrogen Experiment (Cold Finger Apparatus)}

The capability of the aerogel to insulate a cold metal surface below $20 \mathrm{~K}$ and eliminate formation of free LN2 was tested using a novel liquid nitrogen production method. This cold finger apparatus uses gravity to visually determine if any collection and movement of nitrogen in the liquid state occurs when the cold surface is insulated with aerogel material. The ET intertank crevice is also simulated in that it does not positively contain LN2 that may collect. The cold finger apparatus has slits in the bottom analogous to the shim gaps in the intertank flange joint. The apparatus consists of a stainless steel cooling coil inside a clear plastic pipe with slits cut just above a bottom foam plug. The pipe is filled with aerogel beads (or left empty) and purged with gaseous nitrogen. The cooling coil is supplied from a vacuum-jacketed transfer hose connected to a LHe dewar as shown in Figure 4.

Three different experimental configurations were made using the cold finger apparatus. Configuration one with no aerogel insulation is shown in Figure 5. In this case the free LN2 began flowing from the tip six minutes into the test, and flowed continuously for duration of the $1 / 2$ hour test. The rate of nitrogen liquefaction was approximately 0.42 milliliter per second as measured by weighing LN2 caught in an insulated cup after flowing through the bottom drain slits. At that rate, LN2 could fill the internal volume of the apparatus in about $2 \frac{1}{2}$ hours. Configuration 2 with the cylinder partially filled with aerogel insulation is shown in Figure 6. Even in this atypical case none of the LN2 produced in the exposed cold coil region above the aerogel was able to move to the bottom of the apparatus during the $1 \frac{1}{2}$ hour-long test. The full aerogel insulation, configuration 3, is shown in Figure 7. No LN2 flowed from the apparatus during the entire 4 hour test duration. 


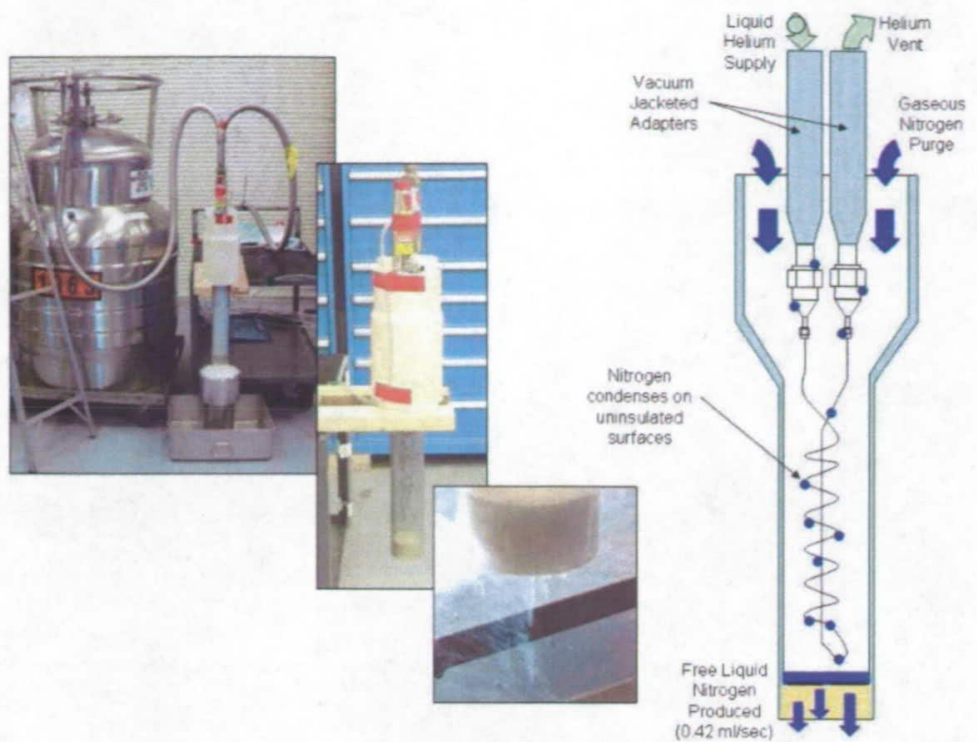

Figure 4. Cold finger experiment with no aerogel insulation inside pipe (configuration 1).
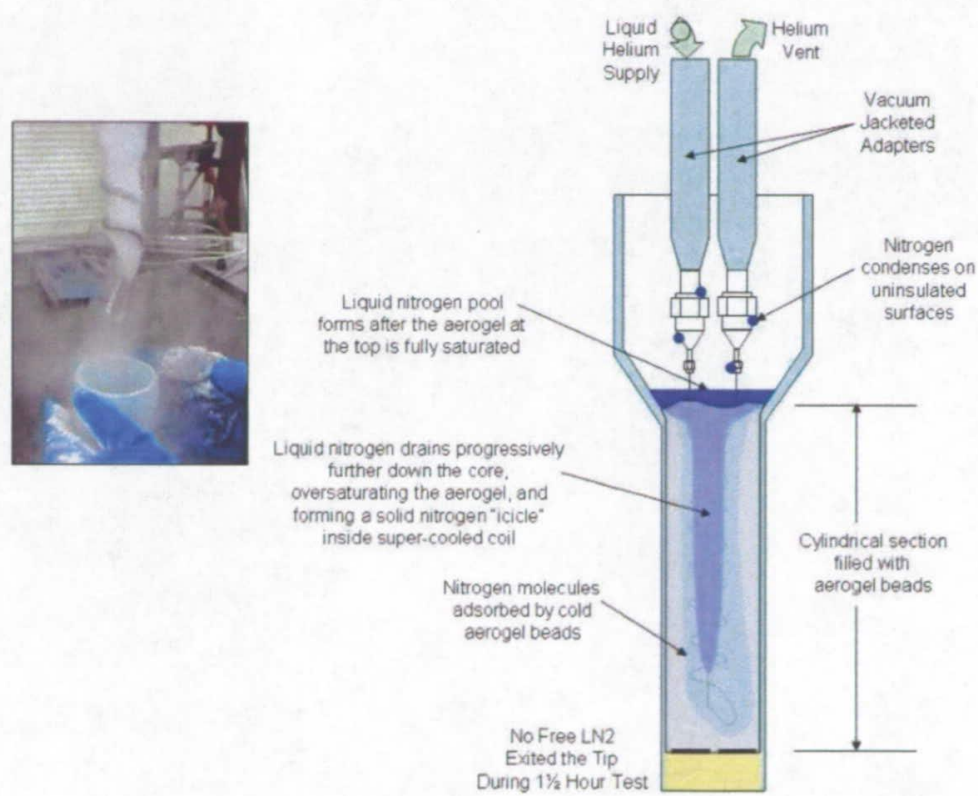

Figure 5. Cold finger experiment with partially-filled aerogel insulation (configuration 2). 

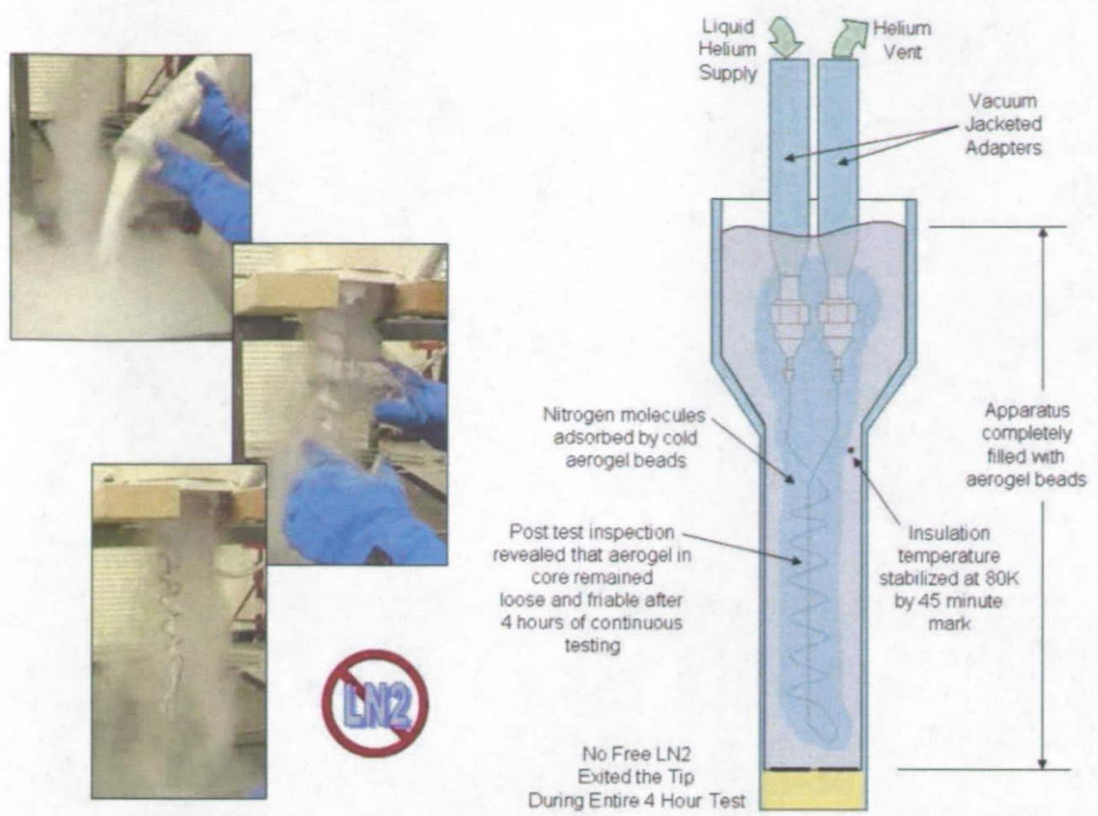

Figure 6. Cold finger experiment with full aerogel insulation inside pipe (configuration 3).

\section{LH2 INTERTANK DEMONSTRATION TEST UNIT}

A demonstration test unit depicted in Figure 7 was designed and constructed to prove out the operational limits of the new aerogel insulation system. The approximately $1 / 10^{\text {th }}$ scale test unit is constructed from thin-wall stainless steel, a G-10 feedthrough for the LHe supply, and an aluminum lid. The crevice profile is approximately full scale (12.7-mm bottom surface and 50-mm exposed cold metal tank surface).

Temperature sensors were located from the bottom of the joint crevice to above the aerogel beads as well as on the tank, on the intertank barrel section, and on the foam surfaces as given in Figure 8. Pressure sensors were used at crevice base and on the lid to measure any pressure difference from top to bottom. The intertank barrel section is designed for full vacuum to allow cryopumping tests for a closed-mass system. SOFI was applied the sides of the unit and the dome of the tank in the specified thicknesses for flight configuration. Additional thicknesses of SOFI were applied to the cryogen feedthrough and the bottom of the unit to provide a stable thermal profile for the tank dome and intertank flange.

The test set-up included LHe supply system from a 42,000-liter tanker, a GN2 supply system, temperature sensors, pressure transducers, a GN2 flow control and metering system, and a full data acquisition system (see Figure 9). Viewports (two each 50 -mm diameter) were included on the top lid for visual examination of the crevice area. Cold helium gas through a spray header on the underside of the tank dome was used to maintain a cold boundary temperature (CBT) of $20 \mathrm{~K}+/-5 \mathrm{~K}$. Two electric tape heaters were affixed to the lid to maintain a warm boundary temperature (WBT) of $300 \mathrm{~K} \mathrm{+/} 2$ $\mathrm{K}$. 


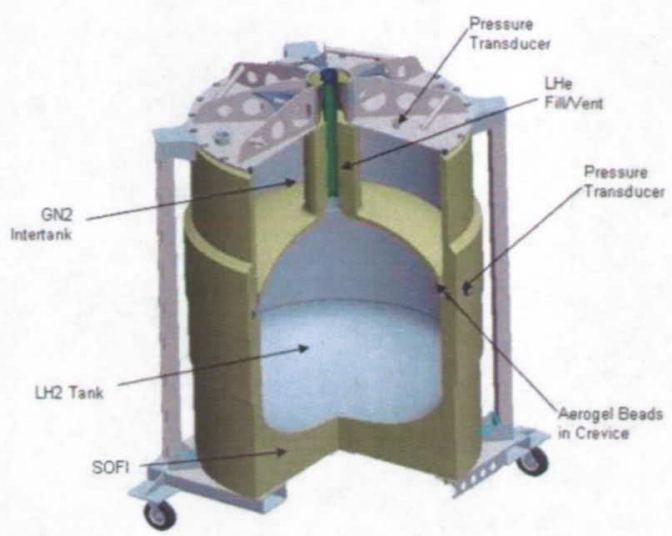

Figure 7. An isometric cutaway view of ET LH2 intertank demonstration test unit showing main features.
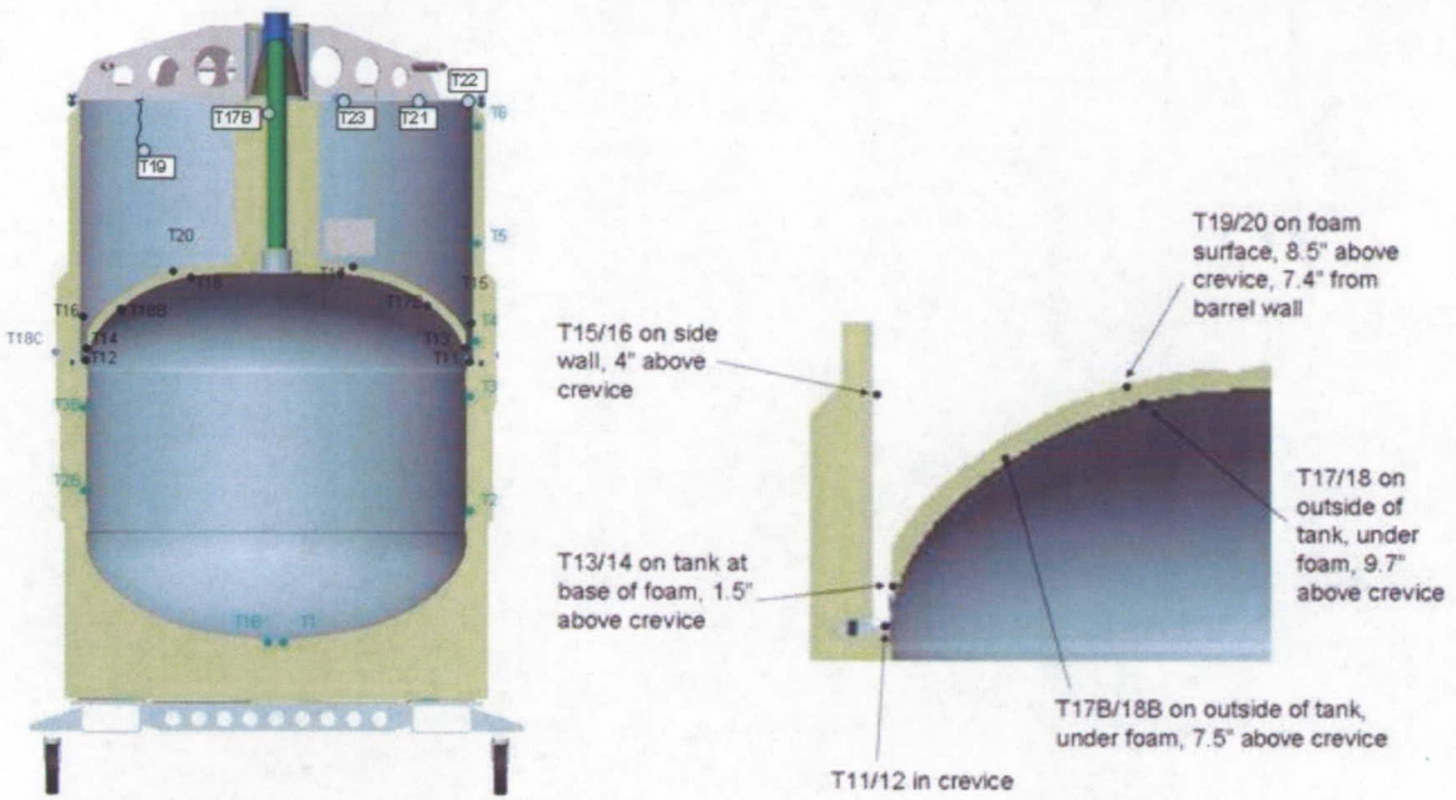

Figure 8. Section view of $1 / 10^{\text {th }}$ scale demonstration test unit showing temperature sensor locations. Close-up view of the full scale intertank crevice area in shown on the right. 

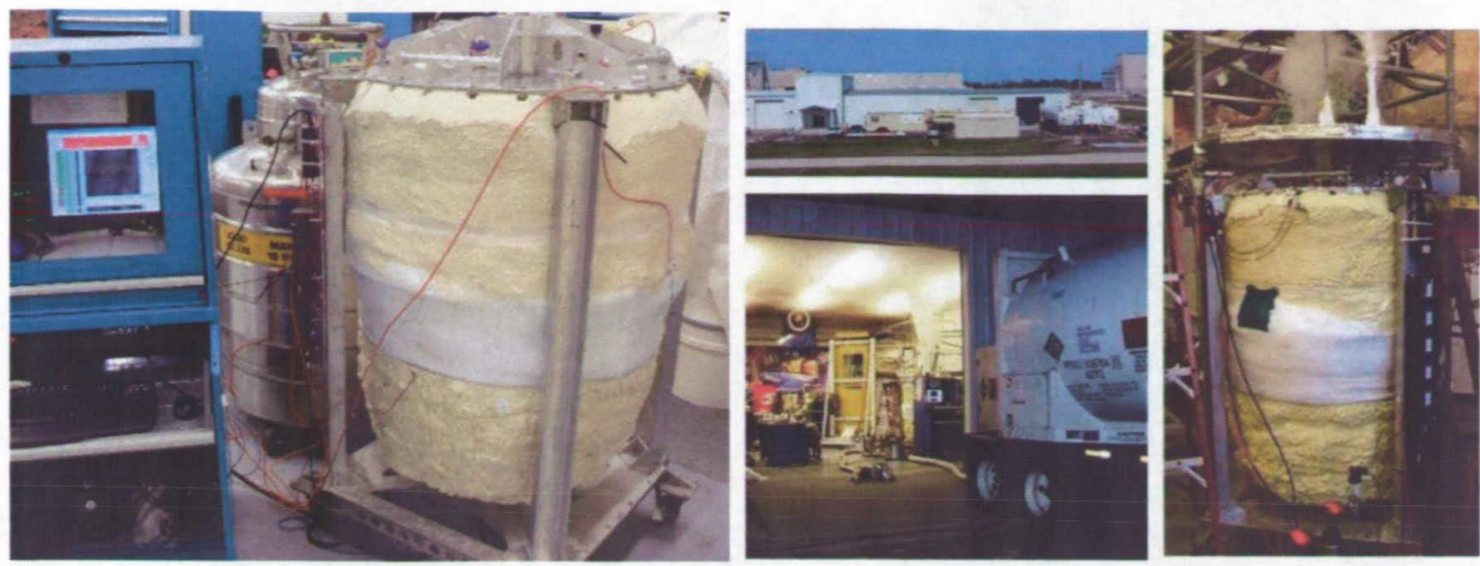

Figure 9. Demonstration testing using the LHe tanker.

\section{TEST RESULTS}

The test results show that production and accumulation of liquid nitrogen in the yjoint crevice region of the intertank is eliminated. Contrary to previous studies to solve this problem, the gas entrapment issue that could cause collateral problems during ascent to orbit is avoided with the breathable aerogel insulation material. Tests were performed in two series.

Test series Part A included two tests performed with a bare crevice and six tests with aerogel insulation installed. The liquid helium tanker enabled continuous liquid helium supply for long duration tests. Control of the warm boundary temperature was improved with the use of two lid heaters and a larger gas deflector to keep the bulk of the cold helium boil-off vapor away from the test article lid. Visual observations were recorded at regular intervals by looking through the two viewports on the lid of the test unit. The results of Part A are summarized as follows:

- Aerogel insulation in the crevice dramatically reduced the amount of nitrogen that was cryopumped within the intertank.

- Aerogel insulation in the crevice generally increased temperatures throughout the intertank.

- Aerogel appearance remained unchanged throughout all testing.

- Visible solid nitrogen did not readily form in the bare crevice.

- LN2 in the bare crevice boiled at the outer edge near the intertank wall.

The totalized mass flow comparing uninsulated versus aerogel insulated tests is given in Figure 9. Photographs of uninsulated tests showing LN2 accumulations are shown in Figure 10. [Add photo of aerogel case even though it doesn't "show" anything] A summary of the steady-state temperatures showing the effect of insulating the cold metal surface of the cavity is given in Figure 11. 


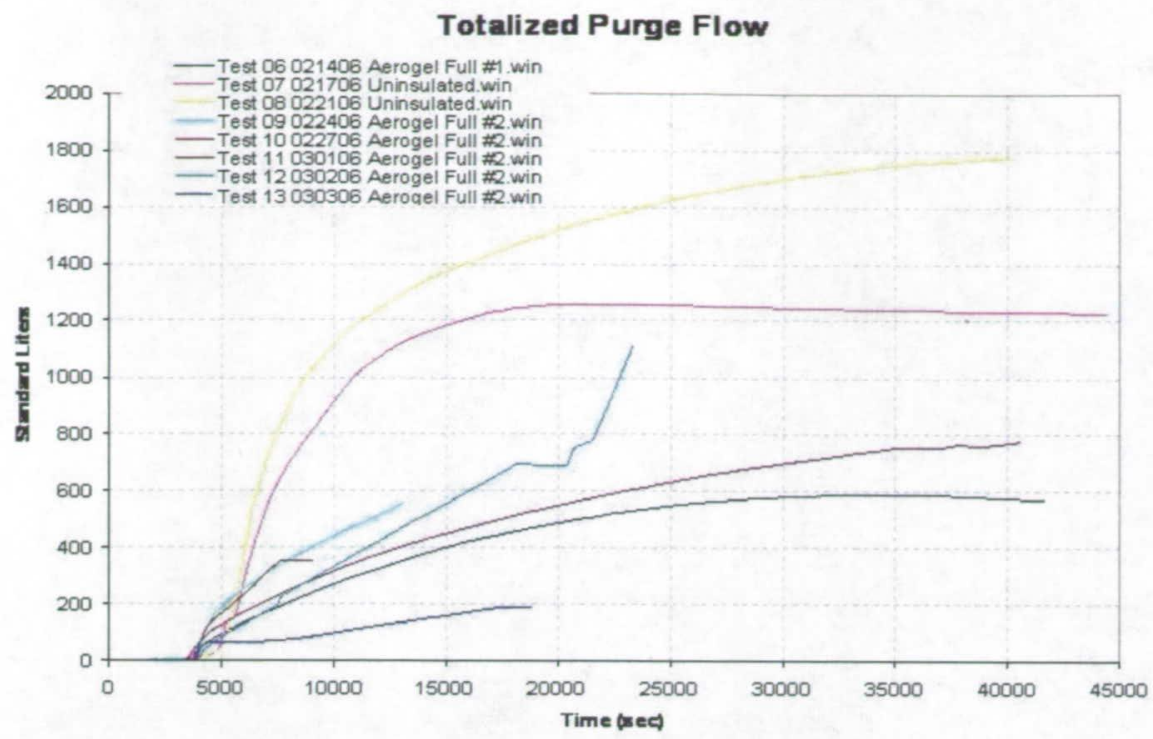

Figure 9. Totalized gaseous nitrogen purge flow for Test series Part A showing effect of uninsulated versus aerogel insulated crevice during cooldown and stabilization phases.

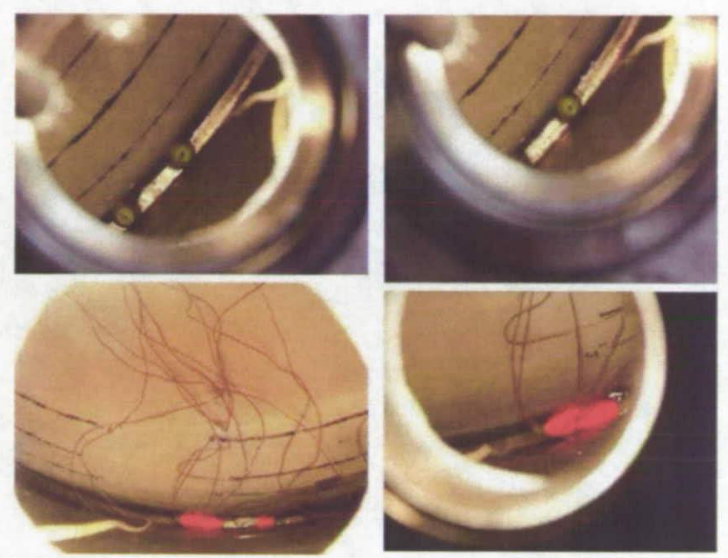

Figure 10. Photographs on left of uninsulated test showing LN2 accumulation inside crevice region. The photograph on the right shows the aerogel insulated test (appearance never changed).

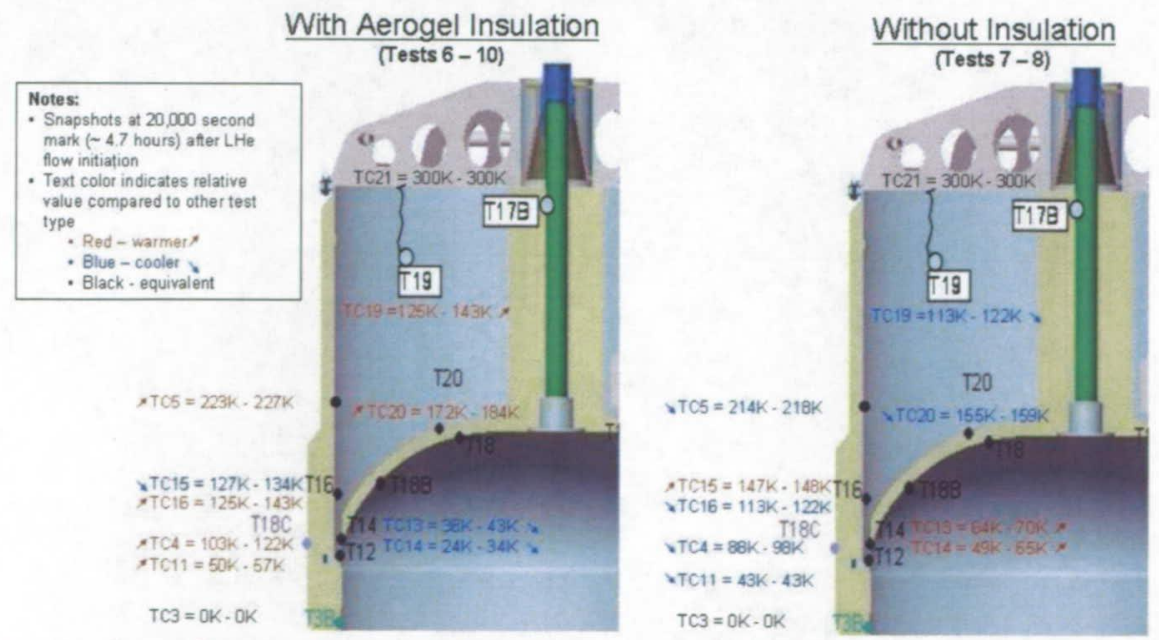

Figure 11. Comparison of tests with and without showing insulation keeps the warm side warm (intertank) and the cold side cold (tank dome). 
Following Part A with quantified GN2 flow, test series Part B was performed to obtain better visual information and physical evidence of the condition of the material in the crevice region. For Part B the GN2 purge flow was maintained as usual to keep a dry nitrogen environment at ambient pressure inside the intertank, but the flow rate was not measured. Viewports were routinely open during the tests and used for access to the crevice area to take measurements, obtain samples, and to probe the aerogel material. The following items were examined: LN2 level versus time, location of solid N2 formation, friability of the aerogel material, and inspection for LN2 in the aerogel material. Photos and video were taken at frequent intervals for all tests. The results from Part B are summarized as follows:

- Minimal aerogel insulation depth is required to prevent LN2 formation.

- Aerogel material remains completely dry and friable (no free LN2).

- Solid nitrogen formation occurs more readily in small amounts of LN2.

- The aerogel insulation system is tolerant of an imperfect installation.

Some cool photographs are given in Figure 12. [Which ones to keep? What to highlight?]
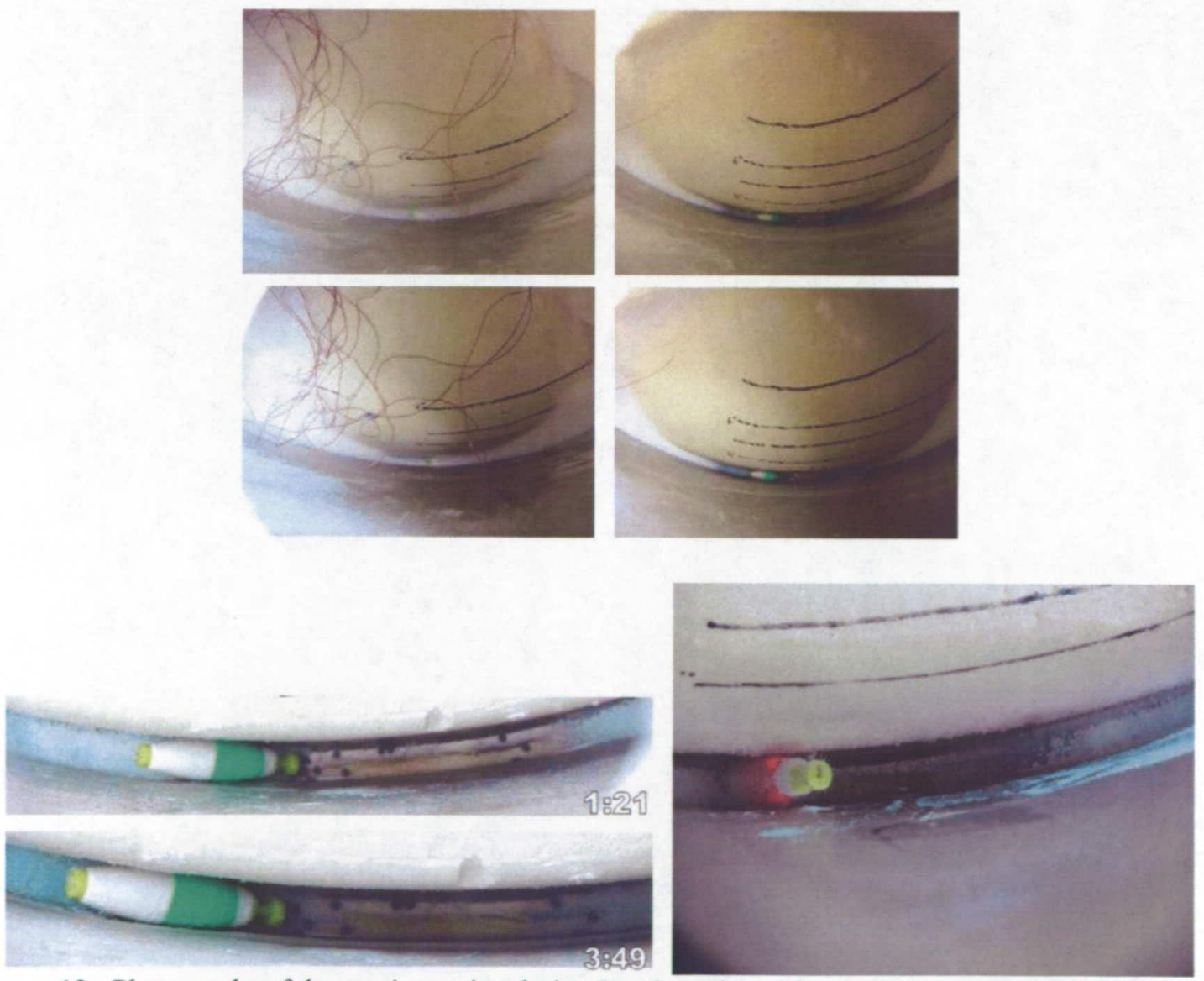

Figure 12. Photographs of the crevice region during Part B testing. The crevice temperature is $20 \mathrm{~K}$. Aerogel material can be seen to darken over time as it saturates with nitrogen. 


\section{ANALYSIS AND DISCUSSION}

A summary of the thermal effect of aerogel beads on the intertank is given in Figure 13. Cleary, the aerogel works to keep the warm side warm and the cold side cold. The depth of aerogel required to prevent nitrogen liquefaction was found to be minimal. In fact, the primary requirement is to simply cover the exposed bare metal portion of the tank dome. In practical terms of execution of the new insulation system on the flight tank, the aerogel will be filled to a level that is convenient to verify by normal means.

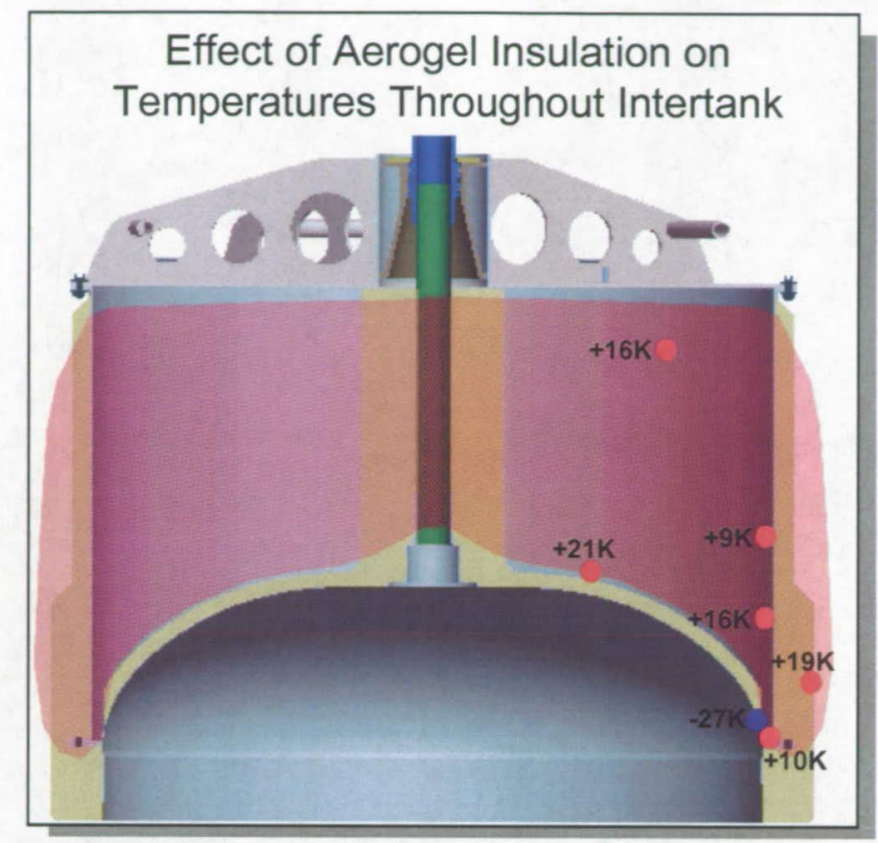

Figure 13. Summary of the effect of the aerogel insulation system on temperatures throughout the intertank. The temperature changes indicated in the figure show test results with aerogel insulation as compared to without insulation.

Beyond the obvious advance in eliminating liquid nitrogen in the crevice region on the ET, the ancillary advantages and disadvantages of the proposed aerogel insulation system have also been considered. The following is a list of some of the advantages to be considered: [chop this way down]

- System uses high thermal performance material

- Aerogel beads (Nanogel) manufactured by Cabot Corporation

- Lowest thermal conductivity at ambient pressure of bulk-fill materials (k-value $\sim 15 \mathrm{~mW} / \mathrm{m}-\mathrm{K}$ )

- Insulate bare metal portion of LH2 tank dome

- Cavity-filling, free-flowing, hydrophobic, fully breathable material

- No adverse effects due to thermal cycling

○ Light weight material (bulk density $\sim 0.080 \mathrm{~g} / \mathrm{cc}$ or $5 \mathrm{lbm} / \mathrm{ft}^{\wedge} 3$ )

- High physisorption capacity of nitrogen

○ About $62 \%$ by volume (LN2: Aerogel) 
- During cooldown, nitrogen molecules are sequestered inside the pores of the aerogel as the temperature of the bead pack comes down

- After cooldown, cryopumping processes are essentially stopped

- Total nitrogen purge uptake is dramatically reduced

- Nearly $1 / 3$ compared to uninsulated case

- Free LN2 in intertank flange and crevice region is eliminated

- For all phases of launch loading operations

- Under both cooldown transient and steady-state long-duration conditions

The only disadvantages identified are associated with installation. The present aerogel insulation system would require installation in the vertical position. In the demonstration unit, the aerogel was found to stay in place even with a forceful impingement of purge gas directed straight downward from the lid. In the flight tank the aerogel would be protected further by three factors: the presence of a stiffening ring immediately above crevice area, the favorable location of purge entrances to the large intertank volume, and the very steep angle and depth of the crevice. An enhanced system using a breathable "capper" material to hold it in place could be developed if needed for installation in the horizontal position.

Important findings also resulted from the baseline un-insulated intertank demonstration tests. Within this test article, there appeared to be a delicate thermodynamic balance that determined whether the nitrogen remained in the liquid state or solidified in the critical area of the intertank flange gap. In one long duration test, solid nitrogen was observed intermittently as it grew partially across the width of the crevice and subsequently melted prior to the end of the test. On other occasions, a probe was used to feel for the bottom of the LN2 filled crevice. This technique indicated over $3 / 4$ " thickness of solid nitrogen formation at the bottom of the crevice near the tank wall and tapering down toward the flange gap. The overall quantity of liquid nitrogen present appeared to affect the likelihood of solidification, with frozen nitrogen occurring more readily in smaller quantities of liquid. Understanding solidification of nitrogen in the intertank is crucial in determining the severity of the problem of liquid nitrogen seeping through the intertank flange.

\section{CONCLUSION}

A new thermal insulation system using aerogel material has been developed to eliminate the problem of liquid nitrogen accumulation within the intertank of the Space Shuttle. The proposed solution is to insulate the exposed cold surface of LH2 tank dome with bulk-fill aerogel material. The aerogel insulation system eliminates all free liquid nitrogen within the crevice and thus removes a cause of foam debris from the intertank flange area. There is also a reduction in flight weight of up to $200 \mathrm{~kg}$. The installation process is straight-forward and no adverse effects have been identified.

The operability of the new aerogel system has been shown through extensive demonstration testing. The experimental design, research, development, and 
demonstration testing were performed by the Cryogenics Test Laboratory at NASA Kennedy Space Center. A total of 16 tests were conducted using liquid helium to provide the necessary cold boundary temperature for LH2 simulation. Laboratory testing of the physical properties, for example liquid nitrogen sorption characteristics, of the aerogel material was also performed.

The new technology can provide thermal performance improvements on future space launch vehicles. The proven use of these aerogel bulk-fill materials and other aerogel-based insulation systems provides new options in the design and maintenance of cryogenic systems.

\section{ACKNOWLEDGEMENTS}

The authors are glad to acknowledge the expert assistance of many engineers and scientists working for Space Shuttle Program including Charlie Stevenson, Trent Smith, and Wes Johnson. This work was supported by the NASA Engineering and Safety Center (NESC) through the leadership of Mike Kirsch and Andreas Dibbern. Thanks to Adam Dokos and team at the NASA Prototype Laboratory for constructing the test unit.

\section{REFERENCES}

1. Fesmire, J.E., "Aerogel insulation systems for space launch applications," Cryogenics, 46, issue 2-3, February 2006, pp. 111-117.

2. Cabot Corporation, http://www.nanogel.com.

3. Fesmire, J.E., Augustynowicz, S.D., and Rouanet, S., "Aerogel Beads as Cryogenic Thermal Insulation System," in Advances in Cryogenic Engineering, Vol. 47, American Institute of Physics, New York, 2002, pp. 1541-1548.

4. Fesmire, J.E., Rouanet, S., and Ryu, J., "Aerogel-Based Cryogenic Superinsulation," in Advances in Cryogenic Engineering, Vol. 44, Plenum Press, New York, 1998, pp. 219-226.

5. Choi, Y.S., M.N. Barrios, H.N. Change, and S.W. Van Sciver, "Thermal conductivity of powder insulations for cryogenic storage vessels," Advances in Cryogenic Engineering, Vol. 51B, American Institute of Physics, New York, 2006.

6. 